DOI: https://doi.org/10.47405/mjssh.v6i3.697

\begin{tabular}{|c|c|}
\hline & Malaysian Journal of Social Sciences and Humanities (MJSSH) \\
\hline 32 & Volume 6, Issue 3, March 2021 \\
\hline 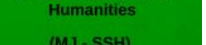 & e-ISSN : 2504-8562 \\
\hline & $\begin{array}{l}\text { Journal home page: } \\
\text { www.msocialsciences.com }\end{array}$ \\
\hline
\end{tabular}

\title{
Tahap Budaya Keusahawanan dan Kepimpinan Keusahawanan serta Hubungannya dengan Minda Keusahawanan Anak-Anak Golongan Asnaf
}

\author{
Muhammad Syafiq Zakaria' ${ }^{1}$, Sheerad Sahid ${ }^{1}$, Norasmah Othman \\ ${ }^{1}$ Fakulti Pendidikan, Universiti Kebangsaan Malaysia (UKM) \\ Correspondence: Sheerad Sahid (sheerad@ukm.edu.my)
}

\begin{abstract}
Abstrak
Kebanyakan negara membangun masih lagi mempunyai kadar kemiskinan yang tinggi dan menjadi salah satu punca kepada masalah tingkah laku, jenayah, kekacauan keluarga dan kegagalan akademik. Untuk memastikan pembangunan sesebuah negara berjalan dengan lancar, perkara berkait dengan kemiskinan perlu diberi perhatian serius. Dalam konteks Malaysia, kerajaan telah melakukan pelbagai usaha dalam menangani kemiskinan terutamanya bagi golongan Asnaf iaitu dengan mewujudkan Program Keusahawanan Asnaf oleh Lembaga Zakat Negeri. Tujuan kajian ini dijalankan adalah bagi mengenal pasti tahap budaya keusahawanan dan kepimpinan keusahawanan serta hubungannya dengan minda keusahawanan bagi anak-anak golongan Asnaf di negeri Selangor. Reka bentuk tinjauan dan kaedah persampelan rawak telah digunakan. 350 sampel anak-anak golongan Asnaf di semua daerah negeri Selangor telah mengambil bahagian. Borang soal selidik adalah sebagai instrumen kajian. Hasil analisis menunjukkan bahawa tahap budaya keusahawanan, kepimpinan keusahawanan serta tahap minda keusahawanan adalah tinggi. Manakala, terdapat korelasi yang positif dan signifikan antara budaya keusahawanan dan kepimpinan keusahawanan terhadap minda keusahawanan anak-anak golongan Asnaf di negeri Selagor. Maka, anak-anak golongan Asnaf ini mempunyai efikasi yang tinggi untuk menjadi seorang usahawan. Implikasi daripada kajian ini membantu Lembaga Zakat Negeri dalam memilih peserta yang benar-benar layak iaitu mereka yang mempunyai tahap budaya keusahawanan, kepimpinan keusahawanan serta minda keusahawanan yang tinggi bagi menyertai Program Keusahawanan Asnaf pada masa akan datang.
\end{abstract}

Kata kunci: keusahawanan asnaf, budaya keusahawanan, kepimpinan keusahawanan, minda keusahawanan

\section{The Level of Entrepreneurial Culture and Entrepreneurial Leadership and Its Relationship with the Entrepreneurial Mindset of Asnaf Children}

\begin{abstract}
Most developing countries still have high poverty rates and are one of the causes of behavioral problems, crime, family unrest and academic failure. To ensure the development of a country runs smoothly, matters related to poverty need serious attention. In the context of Malaysia, the government has made various efforts in tackling poverty, especially for the Asnaf group, namely by creating the Asnaf Entrepreneurship Program by the State Zakat Board. The purpose of this study is to identify the level of entrepreneurial culture and entrepreneurial leadership as well as its relationship with the entrepreneurial mindset for the children of the Asnaf group in the state of Selangor. Survey designs and random sampling methods were used. 350 samples of Asnaf children in all districts of Selangor have
\end{abstract}


participated. Questionnaire form is as a research instrument. The results of the analysis indicated that the level of entrepreneurial culture, entrepreneurial leadership as well as the level of entrepreneurial mindset is high. Meanwhile, there is a positive and significant correlation between entrepreneurial culture and entrepreneurial leadership to the entrepreneurial mindset of Asnaf children in Selagor state. Thus, the children of the Asnaf group have high efficacy to become an entrepreneur. The implications of the study can contributes to the Lembaga Zakat Negeri in selecting participants, namely those who have a high level of entrepreneurial culture, entrepreneurial leadership and entrepreneurial mindset to participate in the Asnaf Entrepreneurship Program in the future.

Keywords: asnaf entrepreneurship, entrepreneurial culture, entrepreneurial leadership, entrepreneurial mindset

\section{Pengenalan}

Kajian Kemiskinan adalah punca kepada pelbagai masalah dalam masyarakat seperti masalah tingkah laku, jenayah, kekacauan keluarga dan kegagalan akademik (Fukuyama, 2017). Perkara berikut telah menjadi isu yang biasa berlaku dalam kebanyakan negara membangun. Sebagai contoh, di Brazil, Argentina, Mexico, Nigeria, Filipina, Thailand, Indonesia dan Malaysia apabila dibuktikan dengan jumlah kes jenayah dan permasalahan sosial yang banyak disebabkan oleh kemiskinan (Islam et al., 2017; Short, 2018; Ravallion, 2019).

Untuk memastikan pembangunan sesebuah negara berjalan dengan lancar, perkara-perkara berkait dengan kemiskinan rakyat perlu diberi perhatian serius. Pengagihan pendapatan yang sama rata dalam kalangan masyarakat juga perlu diberi perhatian (Dabla-Norris et al., 2015). Kemiskinan dan pengagihan pendapatan yang tidak seimbang boleh menjadi isu utama dalam kebanyakkan negara membangun (Fosu, 2017). Oleh itu, pelbagai polisi dan rancangan dilaksanakan bagi tujuan membasmi kemiskinan. Pelan ini penting agar ekonomi antara golongan kaya dan golongan miskin tidak ketara, bererti jurang pendapatan antara kedua-dua golongan dapat dikecilkan (Hussiin, 2018).

Di Malaysia, kerajaan telah menyediakan berbagai bentuk bantuan seperti pembiayaan kewangan bagi membantu usahawan mikro dalam perniagaan (Adnan \& Roselam, 2019). Selain program keusahawanan kecil yang ditubuhkan oleh kerajaan untuk membantu golongan miskin, institusi zakat juga memainkan peranan menolong golongan asnaf dengan memperkenalkan program keusahawanan. Ini kerana bidang keusahawanan telah dikenal pasti sebagai alternatif yang boleh diusahakan oleh semua golongan masyarakat bagi tujuan menjana pendapatan. Dengan menawarkan program keusahawanan kepada golongan asnaf, sebagai contoh, dapat membantu mereka keluar daripada masalah kemiskinan (Najwa, 2017).

Amnya, perbezaan program keusahawanan oleh institusi zakat dan program keusahawanan dari agensi lain adalah dari aspek bantuan yang diberi. Institusi zakat lazimnya akan membantu golongan asnaf memulakan perniagaan dengan memberi bantuan kewangan yang diambil daripada wang zakat Lembaga Zakat Negeri menerusi Program Keusahawanan Asnaf (Abai et al., 2020). Ini kerana salah satu fungsi zakat dalam Islam adalah untuk membantu meringankan beban yang ditanggung oleh golongan miskin (Hassanain, 2015). Justeru, zakat sepatutnya dapat membantu golongan asnaf, manakala bagi Muslim yang berkelayakan dan memenuhi kriteria wajib menunaikan salah satu rukun Islam ini. Allah berfirman dalam Al-Quran:

"Ambillah sedekah dari harta mereka, sehingga mereka dapat dibersihkan (dari dosa) dan disucikan (dari perbuatan buruk), dan berdoalah untuk mereka, kerana sesungguhnya doa-doamu akan memberi mereka penghiburan. Dan (ingatlah) Allah Maha Mendengar, Maha Mengetahui ”. (Surah AtTaubah 9: 103)" 
Program Keusahawanan Asnaf menerusi bantuan pembiayaan zakat telah menempuh kegagalan (Zainal et al., 2016). Punca kepada kegagalan ini adalah disebabkan oleh kekurangan latihan, bimbingan, pengurusan dan pemantauan dari badan yang menyalurkan pembiayaan kepada golongan Asnaf (Marzuki et al, 2019). Justeru, budaya keusahawanan, kepimpinan keusahawanan dan minda keusahawanan mempunyai kaitan dengan keberhasilan keusahawanan asnaf. Secara khusus, budaya keusahawanan adalah sistem kepercayaan dan nilai tentang bagaimana sesuatu berfungsi dengan membentuk suatu tindakan anggotanya berdasarkan susunan struktur organisasi bagi menghasilkan norma tingkah laku (Gabrielsson et al., 2014).

Seterusnya, kesinambungan budaya keusahawanan ini dapat mewujudkan kepimpinan keusahawanan (Sklaveniti, 2017). Kepimpinan secara amnya adalah melibatkan aktiviti kumpulan yang teratur ke arah pencapaian matlamat (Yunus \& Ahmad, 2016). Manakala, kepimpinan keusahawanan melibatkan penetapan tujuan yang jelas, mewujudkan peluang, memperkasakan individu dan mengawal organisasi oleh usahawan (Zainol et al., 2018). Kepimpinan keusahawanan juga adalah proses mempengaruhi prestasi ahli kumpulan ke arah pencapaian matlamat organisasi yang boleh memanfaatkan peluang keusahawanan (Harrison et al., 2016).

Telah diakui bahawa konsep kepimpinan keusahawanan adalah kompleks dan besar, justeru minat penyelidikan mengenainya terus dilakukan dari berbagai peringkat (Haynes et al., 2015; Galloway et al., 2015). Kepimpinan keusahawanan adalah penting kerana kepentingan individu diperlukan dalam proses keusahawanan. Perkara tersebut diselaraskan dengan penyelidikan semasa dalam kepimpinan keusahawanan dengan penekanan kepada sifat-sifat usahawan seperti berkeyakinan tinggi dan berani mengambil risiko (Renko et al., 2015; Volery et al., 2015). Justeru, budaya keusahawanan dan kepimpinan keusahawanan ini berkait rapat dengan minda keusahawanan.

Seterusnya, minda keusahawanan adalah orientasi individu menangani situasi, tetapi ia bersifat tersembunyi (Klein, 2017; Subramaniam et al., 2020). Dalam konteks keusahawanan strategik ada menyatakan bahawa minda keusahawanan dapat didorong oleh budaya dan kepimpinan keusahawanan (Dweck, 2017).

Menurut Lembaga Zakat Selangor (2019), yang menjadi perintis kepada Program Keusahawanan Asnaf di Malaysia melaporkan bahawa program tersebut menemui kegagalan daripada beberapa individu yang telah menyertai. Isu kegagalan peserta yang menyertai program tersebut adalah merupakan pembaziran kepada wang yang disalurkan oleh pembayar-pembayar zakat. Ketirisan wang pembayar zakat kepada peserta-peserta yang tidak layak menyertai merupakan suatu pembaziran. Objektif utama Program Keusahawanan Asnaf adalah supaya peserta dapat berdikari dalam meneruskan kehidupan dan seterusnya dapat keluar daripada belenggu kemiskinan yang dihadapi. Justeru, kajian ini dijalankan adalah bagi mengetahui apakah tahap budaya keusahawanan, kepimpinan keusahawanan dan tahap minda keusahawanan yang dimiliki. Manakala, hubungan antara budaya keusahawanan dan kepimpinan keusahawanan terhadap minda keusahawanan turut dikaji.

\section{Sorotan Literatur}

\section{Budaya Keusahawanan}

Kajian mengenai budaya keusahawanan telah menjadi topik yang meningkat naik dan popular bagi pengkaji-pengkaji dalam bidang sains sosial sama ada di Malaysia dan luar negara (Ishak et al, 2017; Capelleras et al, 2019). Budaya digambarkan sebagai pengaturcaraan minda kolektif yang membezakan anggota satu kumpulan atau kategori orang dengan yang lain (De Mooij, 2015). Budaya keusahawanan pula adalah nilai dan norma yang membawa kepada penerimaan ketidakpastian dan pengambilan risiko (Kirkley, 2016).

Dalam bahagian ini, beberapa dimensi budaya akan dibincangkan berdasarkan kajian lepas antaranya dimensi autonomi, inovasi, berani mengambil risiko, budaya proaktif dan daya saing agresif. Budaya keusahawanan berkait rapat dengan sifat autonomi seseorang, pemangkin kepada individu dalam 
mendorong aktiviti keusahawanan adalah kebebasan yang diperlukan bagi mewujudkan sesuatu yang baru (Jabeen, 2017; Mehtap, 2017). Justeru, dimensi autonomi adalah penting dalam budaya keusahawanan. Maka, sifat autonomi boleh mendorong usahawan asnaf bertindak secara bebas dan mencari peluang tanpa adanya kekangan luaran.

Menurut Halim et al., (2015), budaya keusahawanan yang berinovasi adalah kesinambungan daripada sifat autonomi. Dimensi inovasi memainkan peranan dalam mewujudkan keusahawanan. Budaya berinovasi merupakan budaya individu dalam mencorakkan idea baru, bereksperimen, penyelesaian baru terhadap masalah dan proses kreatif usahawan (Nambisan et al., 2018; Yun et al., 2020). Impak positif dalam budaya inovasi akan mewujudkan usahawan yang dapat menghasilkan nilai dalam teknologi, produk dan perkhidmatan yang ditawarkan (Halim et al., 2015).

Antara budaya keusahawanan yang banyak disebut oleh penyelidik adalah individu yang berani dan bersedia mengambil risiko (Shepherd et al., 2015; Krueger et al., 2017 \& Wales et al., 2019). Individu yang bersedia menerima ketidakpastian dan kebimbangan yang tidak menentu dalam perniagaan adalah mereka yang dianggap sebagai usahawan. Justeru, usahawan asnaf perlu mempunyai orientasi berani mengambil risiko sebagai budaya keusahawanan yang diperlukan demi menyelesaikan masalah dan memperoleh keuntungan. Sifat berani mengambil risiko memerlukan sumber daya yang tinggi sebagai pemangkin kepada usahawan asnaf bagi mencapai kejayaan dalam perniagaan.

Seterusnya, budaya keusahawanan proaktif merupakan kesinambungan daripada budaya berinovasi, autonomi dan bersedia mengambil risko. Budaya keusahawanan proaktif merupakan budaya yang menekankan inisiatif keusahawanan dengan mendorong pencarian peluang serta terlibat dalam pasaran baru. Individu yang proaktif adalah mereka yang dapat memanfaatkan peluang baru dengan konsep yang tersendiri (Lumpkin \& Dess, 1996). Maka, Usahawan Asnaf perlu menerapkan budaya keusahawan proaktif demi kelangsungan perniagaan.

Penyelidik dalam budaya keusahawanan juga ada menyebut mengenai budaya keusahawanan berdaya saing agresif (Shafique \& Kalyar, 2018 \& Hu et al., 2018). Daya saing agresif merujuk kepada kecenderungan budaya yang berorientasikan pencapaian dengan mencabar para pesaing di samping dapat meningkatkan kedudukan mereka berbanding firma lain (Cameron \& Quinn, 2019). Budaya berdaya saing agresif merupakan komponen penting kerana perniagaan baru lebih cenderung untuk gagal berbanding dengan perniagaan yang mapan. Justeru, budaya berdaya saing agresif perlu diterapkan kepada setiap usahawan asnaf demi pengukuhan perniagaan yang dijalankan.

\section{Kepimpinan Keusahawanan}

Kepimpinan keusahawanan wujud di antara persimpangan maksud keusahawanan dan kepimpinan. Kepimpinan adalah proses pengaruh (Silva, 2014; Ruben et al., 2016) manakala keusahawanan sebagai proses di mana peluang dapat mencipta barang dan perkhidmatan masa depan yang ditemui, dinilai dan dieksploitasi (Oviatt et al., 2015). Manakala, kepimpinan keusahawanan adalah proses mempengaruhi orang lain untuk memahami dan bersetuju tentang apa yang perlu dilakukan secara kolektif demi mencapai objektif bersama (Silva, 2014).

Pertindihan antara keusahawanan dan kepimpinan telah dikaji oleh beberapa penyelidik (Hasrul, 2016; Leitch \& Volery; 2017). Justeru, beberapa ciri telah muncul apabila kedua bidang ini bersatu antaranya visi, fokus peluang, pengaruh kepada pengikut, perancangan, motivasi kepada orang lain, pencapaian orientasi, kreativiti pemimpin dan pengikut, fleksibiliti, kesabaran, kegigihan, pengambilan risiko, toleransi, ketabahan, keyakinan diri, orientasi kuasa, proaktif dan lokus kawalan dalaman (Renko et al., 2015; Harrison et al., 2018; Engelen et al., 2015). Walaupun sifat kepimpinan keusahawanan berikut telah dikaji namun, kajian ini akan memfokuskan kepada sifat, tingkah laku dan tindakan pemimpin keusahawanan.

Perbezaan sifat, tingkah laku dan tindakan yang mencirikan kepimpinan keusahawanan dengan gaya kepimpinan yang lain adalah dengan memfokuskan tujuan keusahawanan itu sendiri bagi pengiktirafan kepada peluang untuk dieksploitasi (Renko et al., 2015). Pemimpin perlu mempunyai inisiatif dalam 
memperkenalkan barang atau perkhidmatan yang inovatif ke pasaran. Manakala, ekploitasi membawa maksud yang berbeza iaitu aktiviti dan pelaburan yang dilakukan bagi memperoleh pulangan daripada peluang baru (Nieto et al., 2016). Justeru, pemimpin dalam konteks usahawan perlu mempunyai ciriciri berikut supaya peluang yang datang dapat digunakan sebaik mungkin.

Pemimpin keusahawanan sering terlibat dalam aktiviti yang berfokus kepada peluang dengan mempengaruhi pengikutnya dalam melakukan tingkah laku keusahawanan (Mokhber et al., 2016). Antara sebab mengapa pemimpin perlu fokus kepada peluang adalah kerana pemimpin merupakan penggerak dalam proses eksploitasi kepada peluang baru bagi sesebuah organisasi. Justeru, komitmen bagi setiap pengikut adalah penting dalam melakukan apa yang telah dirancang oleh pemimpin. Tugas pemimpin juga adalah untuk mempengaruhi dan mengarah pengikutnya dengan bertindak sebagai role model (Jyoti \& Bhau, 2015). Justeru, pemimpin dan pengikutnya perlu bekerjasama dalam mendapatkan sumber dan mengenali peluang baru untuk dimanfaatkan.

Selain berperanan sebagai role model, pemimpin usahawan juga perlu mendorong pengikutnya untuk mencapai tujuan keusahawanan. Pemimpin perlu mendorong pengikutnya dari segi berfikir dan bertindak dengan cara yang lebih inovatif. Visi keusahawanan perlulah jelas untuk masa depan firma dalam jangka masa panjang. Pemimpin juga bertanggungjawab kepada pengikutnya dalam mentafsir identiti mereka dalam syarikat iaitu sebagai ejen yang bertanggungjawab terhadap kejayaan masa depan.

Kepimpinan keusahawanan secara konseptual adalah berbeza dengan konsep kepimpinan yang lain. Namun, secara konstruknya masih selaras dengan kepimpinan transformasi (Bass \& Avolio, 1995) dan kepimpinan peningkatan kreativiti (Makri \& Scandura, 2010). Kedua-dua jenis kepimpinan ini adalah lanjutan daripada kepimpinan keusahawanan.

Secara konseptual, kepimpinan keusahawanan ini berbeza dengan konsep kepimpinan yang lain, namun konstruknya masih selaras dengan dua gaya kepimpinan ini: kepimpinan transformasi dan kepimpinan peningkatan kreativiti (Makri \& Scandura, 2010). Kedua-dua jenis kepimpinan ini adalah lanjutan daripada kepimpinan keusahawanan.

Kepimpinan transformasi terdiri daripada empat komponen: pemodelan peranan berkarisma, pertimbangan individu, motivasi dan rangsangan intelektual. Konstruk berikut telah digunakan secara meluas dalam penyelidikan keusahawanan (Jyoti \& Bhau, 2015; Mittal \& Dhar, 2015; Hoch et al., 2018). Pemimpin transformasi turut menunjukkan beberapa ciri dan tingkah laku seperti pemimpin keusahawanan, seperti mencari sesuatu yang baru dan mencari peluang dalam menghadapi risiko. Justeru, pemimpin transformasi mendorong pengikutnya untuk memikirkan masalah lama dengan cara penyelesaian baru dan menyebabkan penemuan peluang baru. Ciri ini adalah jelas sebagai pertindihan antara kepimpinan keusahawanan dan kepimpinan transformasi.

Terdapat perbezaan antara kepimpinan keusahawanan dan kepimpinan transformasi. Pemimpin transformasi lebih menyedari keperluan dan kebolehan unik pengikutnya, membina hubungan dengan pekerjanya, memahami dan mempertimbangkan kemahiran mereka (Mittal \& Dhar, 2015). Manakala pemimpin keusahawanan hanya mempertimbangkan pengikut yang mempunyai semangat keusahawanan. Kunci dalam memahami kepimpinan keusahawanan adalah dengan memberi tumpuan kepada tingkah laku yang berorientasikan peluang, sama ada daripada pemimpin ataupun pengikutnya. Walaupun pemimpin transformasi mempunyai elemen tingkah laku ini, namun sifatnya adalah berbeza.

Selain itu, kepimpinan peningkatan kreativiti juga berkaitan dengan kepimpinan keusahawanan. Kepimpinan peningkatan kreativiti membawa maksud kemampuan pekerja untuk menghasilkan idea yang bernas, menyatakan pemikiran yang unik dan membuat penembusan peluang yang luar biasa (Makri \& Scandura, 2010). Gaya kepimpinan ini menunjukkan subordinat akan lebih kreatif apabila mereka menganggap pemimpin terdekat menyokong pekerjaannya (Jaiswal \& Dhar, 2015).

Penyelidik lain juga telah menyokong gaya kepimpinan di atas dengan mengembangkan skala kelakuan kreativiti yang mengukur tingkah laku pemimpin seperti memuji karya kreatif pekerja dan menyedari 
usaha inovasi mereka (Renko et al., 2015). Karya kreatif dan usaha inovasi pekerja ini dapat mengkomersialkan produk dan perkhidmatan secara lebih luas. Justeru, kepimpinan keusahawanan, kepimpinan transformasi dan kepimpinan peningkatan kreativiti adalah saling berkait dan boleh diaplikasikan kepada usahawan-usahawan Asnaf.

\section{Minda Keusahawanan}

Topik mengenai minda keusahawanan merupakan kajian ilmiah yang menarik minat beberapa pengkaji dalam bidang keusahawanan (Ireland et al., 2003; Ananda et al., 2016; Nor Hazwani \& Sheerad, 2020; \& Subramaniam et al., 2020). Minda keusahawanan adalah tingkah laku manusia yang mempunyai kecenderungan pemikiran untuk meneroka, menilai, dan memanfaatkan peluang terhadap aktiviti dan hasil keusahawanan yang diinginkan (Bosman \& Fernhaber, 2018). McGrath dan MacMillan (2000) berpendapat bahawa seseorang itu telah mempunyai pemikiran keusahawanan sekiranya mereka telah mula bertindak dan berfikir sebagai usahawan lain.

Justeru, pemimpin keusahawanan perlu mempunyai minda keusahawanan yang boleh digunakan untuk mendorong tingkah laku keusahawanan (Renko et al., 2015). Terdapat tiga corak pemikiran yang membolehkan pemimpin melibatkan organisasi mereka ketika menghadapi situasi yang tidak menentu. Tiga minda keusahawanan tersebut adalah pemikiran berorientasikan orang, pemikiran berorientasikan tujuan dan pemikiran berorientasikan pembelajaran. Menurut Obschonka dan Stuetzer (2017), pemikiran berorientasikan orang dikelaskan kepada dua iaitu pemimpin yang kekal inklusif dan terbuka; dan pemimpin yang bersikap positif dan menghargai subordinat. Komponen ini dapat mewujudkan pemimpin yang memperoleh sokongan dan kepercayaan pekerja dan ahli pasukan mereka. Ini sangat penting untuk mewujudkan budaya keusahawanan dalam organisasi dan mencetuskan pemikiran dan tindakan keusahawanan dalam kalangan pekerja. Kemampuan para pemimpin untuk tetap terbuka dan inklusif memungkinkan mereka mendapat sokongan dari subordinat, bahkan pihak berkepentingan luar. Maka, minda keusahawanan yang berorientasikan orang dapat mempengaruhi pilihan tindakan keusahawanan.

Seterusnya, pemikiran berorientasi orang mempunyai kaitan dengan pemikiran berorientasikan tujuan (Duening \& Metzger, 2017). Keseimbangan antara orientasi manusia dan orientasi tujuan menjadi pemangkin tindakan kepada pemimpin keusahawanan (Kirkley, 2016). Minda keusahawanan berorientasikan tujuan menjadikan pemimpin keusahawanan bersabar dalam jangka masa panjang kerana fokus yang kuat terhadap tujuan yang ingin dicapai. Pemimpin keusahawanan harus menyedari bahawa perjalanan sebagai seorang usahawan tidak mudah dan pendek, mereka perlu mempercayai sebab-sebab untuk terus menjadi usahawan. Hasil yang mungkin dapat dicapai daripada minda keusahawanan berorientasikan tujuan adalah visi dan misi firma dapat dicapai.

Manakala, pemikiran berorientasikan pembelajaran terbahagi kepada dua komponen iaitu usahawan yang mendengar dan memilih isyarat dari semua pihak; ataupun usahawan yang bereksperimen (Subramaniam \& Shankar, 2020). Namun, kedua-dua komponen tersebut mempunyai persamaan iaitu dapat memotivasikan subordinat kerana mereka terlibat dalam tindakan keusahawanan.

Jelaslah bahawa minda keusahawanan para usahawan ini berkait rapat dengan cara berfikir yang berorientasikan orang, tujuan ataupun pembelajaran. Penglibatan subordinat dalam tindakan keusahawanan juga adalah penting demi kelangsungan firma.

\section{Teori Tindakan Beralasan dan Teori Tingkah Laku Terancang}

Tingkah laku yang berjaya ditunjukkan bergantung kepada tahap kawalan seseorang terhadap faktor dalaman dan luaran yang boleh mengganggu pelaksanaan tindakan. Sejauh mana pencapaian tujuan tingkah laku bergantung kepada kemahiran, kebolehan, kehendak, peluang dari satu tingkah laku kepada tingkah laku lain. Kejayaan ataupun kegagalan tingkah laku di atas faktor tersebut bukanlah suatu pertimbangan kerana ia berada dalam kawalan sukarela; satu-satunya penentu tingkah laku tersebut adalah niat untuk melaksanakannya. Bukti bagi hubungan niat-tingkah laku yang kuat telah ditemukan dalam banyak aplikasi teori Fishbein dan Ajzen (1975 \& 1980) mengenai tindakan 
beralasan. Justeru, penyelidikan ini mempunyai perkaitan dengan teori tindakan beralasan yang menjelaskan perbezaan niat dan tingkah laku.

Teori tindakan beralasan berlaku apabila tingkah laku berada di bawah kawalan sukarela. Ketepatan ramalannya berkurang apabila tingkah laku dipengaruhi oleh faktor kawalan terhad. Justeru, teori tingkah laku terancang (TPB) diusulkan yang memperluaskan teori tindakan beralasan (Ajzen, 1991). Kejayaan kepada usaha untuk melaksanakan rancangan tingkah laku tidak hanya bergantung kepada usaha yang dilakukan, tetapi juga pada kawalan seseorang terhadap faktor-faktor lain seperti maklumat, kemahiran dan kemampuan yang diperlukan.

Menurut teori TPB, penentuan percubaan tingkah laku merangkumi kepercayaan terhadap kemungkinan kepada kejayaan atau kegagalan. Secara umum, seseorang akan berusaha untuk melakukan tingkah laku jika dia percaya bahawa kelebihan kejayaan tersebut melebihi kegagalan dan kepada siapa dia termotivasi untuk tingkah laku. Usahawan yang mempunyai sifat mempercayai kepada kejayaan akan berjaya dalam percubaannya jika dia memiliki kawalan yang cukup terhadap faktor dalaman dan luaran serta usaha bagi mempengaruhi tujuan tingkah laku.

Teori tindakan beralasan yang dinyatakan hanyalah untuk mewakili kes khas TPB. Kedua-dua teori ini hampir tiada beza apabila kebarangkalian subjektif dan tahap kawalan terhadap faktor dalaman dan luaran adalah sama. Apabila tingkah laku semata-mata ditunjukkan ia boleh menggunakan teori tindakan beralasan. Namun, apabila kebarangkalian subjektif untuk keberhasilan dan kawalan sebenarnya kurang sempurna domain TPB perlu diterapkan. Maka, kajian ini berkait rapat dengan teori tindakan beralasan dan teori tingkah laku terancang oleh usahawan asnaf.

\section{Model Keusahawanan Strategik}

Minda keusahawanan, budaya keusahawanan dan kepimpinan keusahawanan, pengurusan sumber daya yang strategik, penerapan kreativiti untuk mengembangkan inovasi dan kelebihan daya saing adalah dimensi penting SE. Model SE diadaptasi dalam kajian ini bagi mengkaji budaya dan kepimpinan keusahawanan yang boleh mewujudkan minda keusahawanan golongan Asnaf. Rajah 1 menunjukkan model keusahawanan strategik (SE) yang lengkap.

\section{Rajah 1: Model Keusahawanan Strategik}

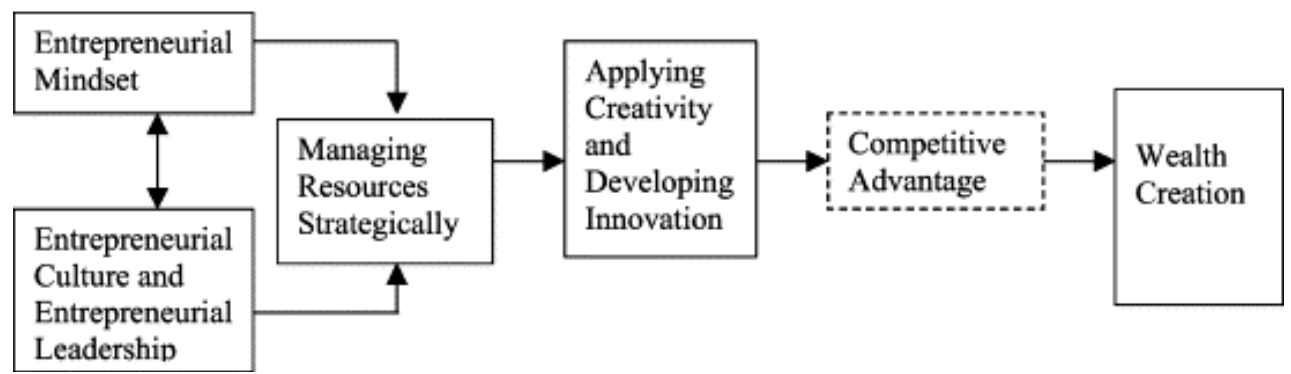

Pengurusan strategik mementingkan pertumbuhan dan penciptaan kekayaan, dan ini merupakan objektif penentu keusahawanan strategik. Pengurusan strategik juga adalah proses memahami perbezaan antara penciptaan kekayaan syarikat dalam pelbagai ekonomi. Justeru, bidang keusahawanan semakin dilihat sebagai rangsangan kepada penciptaan kekayaan di negara-negara membangun dan maju sebagai hasil daripada tindakan setiap syarikat (Ireland et al., 2003).

Konstruk SE yang digunakan dalam kajian ini adalah sebagai pemahaman tentang bagaimana usahawan dapat mewujudkan minda keusahawanan yang diperlukan dalam menguruskan firma. Justeru, keusahawanan asnaf dan beberapa dimensi pengurusan strategik telah diintegrasikan dalam kajian ini. Rumusan daripada sorotan literatur, teori tingkah laku terancang dan model keusahawanan strategik yang telah diterangkan maka terbinalah kerangka konseptual bagi kajian ini. Menurut model dan teori berikut ada menyatakan mengenai tingkah laku seseorang usahawan menerusi budaya dan kepimpinan keusahwanan mempunyai kaitan dengan minda keusahawanan. 


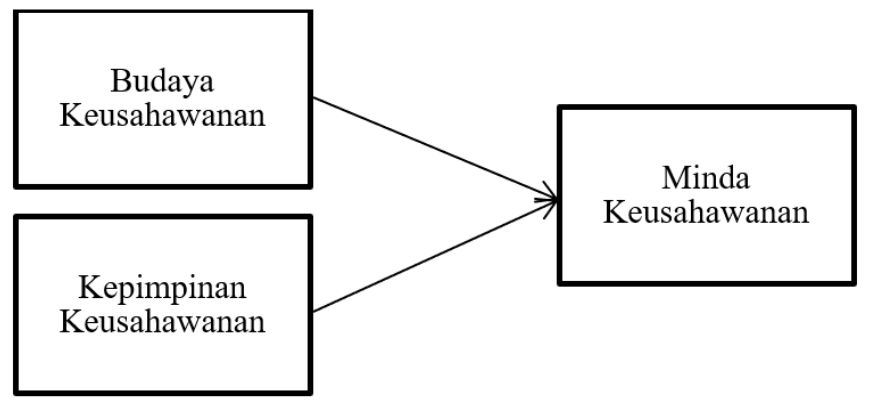

Seperti di Rajah 2, budaya keusahawanan dan kepimpinan keusahawanan merupakan pemboleh ubah bebas, manakala minda keusahawanan pula adalah pemboleh ubah bersandar bagi kajian ini.

\section{Metod Kajian}

Kajian Kajian ini menggunakan pendekatan kuantitatif dengan reka bentuk tinjauan. Populasi kajian ini adalah seramai 44,293 (Kerajaan Negeri Selangor, 2019), yang terdiri daripada anak-anak golongan Asnaf di negeri Selangor. Berdasarkan jadual Krejcie dan Morgan (1970), jumlah sampel yang sesuai adalah sebanyak 380 responden. Walau bagaimanapun, hanya 350 responden sahaja yang memberi respons dan menghantar semula instrumen. Justeru, sampel bagi kajian ini adalah sebanyak 350. Teknik persampelan rawak mudah telah digunakan bagi mengenal pasti sampel yang mewakili setiap daerah di negeri Selangor. Daerah yang terlibat adalah Gombak, Hulu Langat, Hulu Selangor, Klang, Kuala Langat, Kuala Selangor, Petaling, Sabak Bernam dan Sepang.

Borang soal selidik yang digunakan terbahagi kepada tiga bahagian. Bahagian A mengandungi 6 item berkenaan latar belakang responden. Bahagian B mengandungi 20 item mengenai budaya dan kepimpinan keusahawanan, indikator yang diukur adalah mengenai budaya sebagai seorang usahawan dan sifat kepimpinan keusahawanan dalam organisasi. Item di bahagian B diadaptasi daripada Houghton dan Neck (2002). Bahagian C pula mengandungi 10 item mengenai minda keusahawanan. Indikator yang diukur dalam bahagian $\mathrm{C}$ adalah mengenai pemikiran sebagai seorang usahawan. Item di bahagian C diadaptasi daripada Kassim et al., (2014). Kesemua item di bahagian B dan C menggunakan skala Likert lima titik ( $1=$ sangat tidak setuju hingga $5=$ sangat setuju).

Instrumen kajian telah diperiksa oleh dua orang pakar yang mempunyai pengalaman luas dalam bidang keusahawanan yang bertujuan untuk mendapatkan kesahan kandungan dan kesahan muka. Kritikan dan pembetulan telah diambil maklum untuk meningkatkan kesahihan item-item soal selidik. Nilai kesahan instrumen kajian adalah antara 0.39 hingga 0.65. Menurut Lombart (2015), nilai kesahan melebihi 0.35 adalah sangat bermanfaat. Seterusnya, 50 orang anak-anak golongan Asnaf telah terlibat dalam kajian rintis. Hasil kajian rintis menunjukkan pekali kebolehpercayaan bagi pemboleh ubah budaya keusahawanan adalah 0.872 dan item minda keusahawanan mempunyai nilai alfa 0.893 . Menurut Taber (2018), instrumen yang relevan dan baik adalah instrumen yang mempunyai nilai alfa yang sama ataupun melebihi 0.80 .

Bagi mengenal pasti tahap budaya keusahawanan dan kepimpinan keusahawanan dengan minda keusahawanan anak-anak golongan asnaf, statistik deskriptif skor min dan sisihan piawai telah digunakan. Penilaian skor min bagi tahap budaya keusahawanan dan kepimpinan keusahawanan serta minda keusahawanan adalah dengan menggunakan skala berdasarkan Jadual 1. Aplikasi statistik infrensi iaitu analisis ujian korelasi Pearson digunakan bagi hubungan budaya dan kepimpinan keusahawanan terhadap minda keusahawanan. 
DOI: https://doi.org/10.47405/mjssh.v6i3.697

Jadual 1: Interpretasi Skor Min

\begin{tabular}{cc}
\hline Skor Min & Interpretasi Skor Min \\
\hline $\mathbf{1 . 0 0 - 2 . 0 0}$ & Rendah \\
$\mathbf{2 . 0 1 - 3 . 0 0}$ & Sederhana Rendah \\
$\mathbf{3 . 0 1}-4.00$ & Sederhana Tinggi \\
$\mathbf{4 . 0 1 - 5 . 0 0}$ & Tinggi \\
\hline
\end{tabular}

Sumber: Sirkin (2005)

\section{Hasil Kajian}

\section{Tahap Budaya Keusahawanan}

Kajian Pengukuran tahap budaya keusahawanan dinilai daripada keseluruhan min dan kekerapan tertinggi responden kajian. Jadual 2 menunjukkan secara terperinci tentang peratusan dan kekerapan terhadap anak-anak golongan Asnaf di Selangor ke atas kecenderungan budaya keusahawanan yang dimiliki. Analisis min keseluruhan menunjukkan nilai 4.44 dan sisihan piawai 0.79 bagi budaya keusahawanan.

Dapatan menunjukkan bahawa secara keseluruhannya anak-anak golongan Asnaf memiliki tahap kecenderungan budaya keusahawanan yang tinggi. Seterusnya, item 9 "Apabila saya melakukan sesuatu kerja dengan baik, saya akan memberi ganjaran kepada diri sendiri" merekodkan peratusan tertinggi sebanyak 92.6 peratus (Setuju=21.1 peratus dan Sangat Setuju=71.5 peratus). Manakala, item 4 dengan penyataan "Andaian dan kepercayaan kendiri akan digunakan dalam situasi sukar" merekodkan peratusan terendah iaitu 90.5 peratus (Setuju=31.1 peratus dan Sangat Setuju=59.4 peratus).

Justeru, dapatan menunjukkan anak-anak golongan Asnaf yang menjadi sampel kajian mempunyai tahap budaya keusahawanan yang tinggi. Buktinya peratus persetujuaan bagi kesemua item adalah melebihi 90.0 peratus.

Jadual 2: Tahap Budaya Keusahawanan

\begin{tabular}{|c|c|c|c|c|c|c|c|c|c|c|}
\hline \multirow[t]{2}{*}{ Item } & \multicolumn{2}{|l|}{ STS } & \multicolumn{2}{|l|}{ TS } & & \multicolumn{2}{|l|}{ KS } & \multicolumn{2}{|l|}{$\mathbf{S}$} & \multirow{2}{*}{$\begin{array}{l}\text { SS } \\
\%\end{array}$} \\
\hline & No. & $\%$ & No & $\%$ & No. & $\%$ & No. & $\%$ & No. & \\
\hline B1 & 10 & 2.9 & 13 & 3.7 & 8 & 2.3 & 88 & 25.1 & 231 & 66.0 \\
\hline B2 & 3 & 0.9 & 16 & 4.6 & 12 & 3.4 & 117 & 33.4 & 202 & 57.7 \\
\hline B3 & 8 & 2.3 & 13 & 3.7 & 10 & 2.9 & 83 & 23.7 & 236 & 67.4 \\
\hline B4 & 4 & 1.1 & 16 & 4.6 & 13 & 3.7 & 109 & 31.1 & 208 & 59.4 \\
\hline B5 & 9 & 2.6 & 15 & 4.3 & 7 & 2.0 & 109 & 31.1 & 210 & 60.9 \\
\hline B6 & 8 & 2.3 & 11 & 3.1 & 12 & 3.4 & 87 & 24.9 & 232 & 66.3 \\
\hline B7 & 10 & 2.9 & 15 & 4.3 & 6 & 1.7 & 104 & 29.7 & 215 & 61.4 \\
\hline B8 & 10 & 2.9 & 13 & 3.7 & 8 & 2.3 & 105 & 30.0 & 214 & 61.1 \\
\hline B9 & 12 & 3.4 & 7 & 2.0 & 7 & 2.0 & 74 & 21.1 & 250 & 71.5 \\
\hline B10 & 13 & 3.7 & 15 & 4.3 & 3 & 0.9 & 136 & 38.9 & 183 & 52.3 \\
\hline Skor Min & 4.44 & & & & & & & & & \\
\hline Sisishan & & & & & & & & & & \\
\hline Piawai & 0.79 & & & & & & & & & \\
\hline Tahap & Ting & & & & & & & & & \\
\hline
\end{tabular}




\section{Tahap Kepimpinan Keusahawanan}

Pengukuran tahap kepimpinan keusahawanan dinilai daripada keseluruhan min dan kekerapan tertinggi responden kajian. Jadual 3 menunjukkan secara terperinci tentang peratusan dan kekerapan terhadap anak-anak golongan Asnaf di Selangor ke atas kecenderungan kepimpinan keusahawanan yang dimiliki. Analisis min keseluruhan menunjukkan nilai 4.43 dan sisihan piawai 0.81 bagi kepimpinan keusahawanan.

Dapatan menunjukkan bahawa secara keseluruhannya anak-anak golongan Asnaf memiliki tahap kecenderungan kepimpinan keusahawanan yang tinggi. Seterusnya, item 7 "Saya sentiasa menulis tujuan khusus untuk prestasi diri sendiri" merekodkan peratusan tertinggi sebanyak 91.7 peratus (Setuju=27.4 peratus dan Sangat Setuju=64.3 peratus). Manakala, item 14 dengan penyataan "Saya sentiasa mencari aktiviti yang saya gemari dalam pekerjaan saya" merekodkan peratusan terendah iaitu 89.2 peratus (Setuju=24.3 peratus dan Sangat Setuju=64.9 peratus).

Justeru, dapatan menunjukkan anak-anak golongan Asnaf yang menjadi sampel kajian mempunyai tahap kepimpinan keusahawanan yang tinggi. Buktinya peratus persetujuan bagi kesemua item adalah melebihi 90.0 peratus.

Jadual 3: Tahap Kepimpinan Keusahawanan

\begin{tabular}{lllllllllll}
\hline Item & $\begin{array}{l}\text { STS } \\
\text { No. }\end{array}$ & \% & TS & No & \% & No. & $\begin{array}{l}\text { KS } \\
\text { \% }\end{array}$ & No. & $\begin{array}{l}\text { \% } \\
\text { No. }\end{array}$ & $\begin{array}{l}\text { \% } \\
\text { C1 }\end{array}$ \\
C2 & 11 & 3.1 & 13 & 3.7 & 7 & 2.0 & 86 & 24.6 & 233 & 66.6 \\
C3 & 10 & 2.9 & 12 & 3.4 & 9 & 2.6 & 96 & 27.4 & 223 & 63.7 \\
C4 & 8 & 2.3 & 15 & 4.3 & 8 & 2.3 & 109 & 31.1 & 210 & 60.0 \\
C5 & 13 & 3.7 & 11 & 3.1 & 14 & 4.0 & 85 & 24.3 & 227 & 64.9 \\
C6 & 12 & 3.4 & 13 & 3.7 & 6 & 1.7 & 129 & 36.9 & 190 & 54.3 \\
C7 & 6 & 1.7 & 18 & 5.1 & 7 & 2.0 & 100 & 28.6 & 219 & 62.6 \\
C8 & 9 & 2.6 & 11 & 3.1 & 9 & 2.6 & 96 & 27.4 & 225 & 64.3 \\
C9 & 4 & 1.1 & 19 & 5.4 & 8 & 2.3 & 97 & 27.7 & 222 & 63.4 \\
C10 & 13 & 3.7 & 10 & 2.9 & 8 & 2.3 & 101 & 28.9 & 218 & 62.3 \\
Skor Min & 6 & 1.7 & 13 & 3.7 & 12 & 3.4 & 138 & 39.4 & 181 & 51.7 \\
Sisishan Piawai 0.81 & & & & & & & & & \\
Tahap & Tinggi & & & & & & & & & \\
\hline
\end{tabular}

\section{Tahap Minda Keusahawanan}

Minda keusahawanan dinilai daripada keseluruhan item serta kekerapan tertinggi responden kajian seperti di Jadual 4. Min keseluruhan bagi tahap minda keusahawanan anak-anak golongan Asnaf di Selangor adalah 4.44 dan nilai sisihan piawai adalah 0.81. Dapatan tahap minda keusahawanan menunjukkan bahawa secara keseluruhan anak-anak golongan Asnaf di Selangor mempunyai tahap minda keusahawanan yang tinggi. Analisis terperinci mengenai peratusan tertinggi adalah bagi item 1 "Saya boleh menghasilkan idea peningkatan bagi produk atau perkhidmatan yang dijual" berjumlah 94.0 peratus (Setuju=31.4 peratus dan Sangat Setuju=62.6 peratus). Manakala, item 10 dengan penyataan "Saya perlu mempunyai visi perniagaan yang jelas" merekodkan peratusan terendah iaitu 90.3 peratus (Setuju=30.6 peratus dan Sangat Setuju=59.7 peratus). Dapatan membuktikan bahawa anak-anak golongan Asnaf mempunyai minda keusahawanan yang tinggi. Peratus persetujuan menunjukkan kesemua item melebihi 90.0 peratus. 
DOI: https://doi.org/10.47405/mjssh.v6i3.697

Jadual 4: Tahap Minda Keusahawanan

\begin{tabular}{|c|c|c|c|c|c|c|c|c|c|c|}
\hline \multirow[t]{2}{*}{ Item } & \multicolumn{2}{|l|}{ STS } & \multicolumn{2}{|l|}{ TS } & & \multicolumn{2}{|c|}{ KS } & \multicolumn{2}{|l|}{$\mathbf{S}$} & \multirow{2}{*}{$\begin{array}{l}\text { SS } \\
\%\end{array}$} \\
\hline & No. & $\%$ & No & $\%$ & No. & $\%$ & No. & $\%$ & No. & \\
\hline$\overline{\mathrm{D} 1}$ & 8 & 2.3 & 8 & 2.3 & 5 & 1.4 & 110 & 31.4 & 219 & 62.6 \\
\hline D2 & 3 & 0.9 & 21 & 6.0 & 7 & 2.0 & 112 & 32.0 & 207 & 59.1 \\
\hline D3 & 15 & 4.3 & 7 & 2.0 & 9 & 2.6 & 82 & 23.4 & 237 & 67.7 \\
\hline D4 & 13 & 3.7 & 15 & 4.3 & 3 & 0.9 & 104 & 29.7 & 215 & 61.4 \\
\hline D5 & 11 & 3.1 & 14 & 4.0 & 6 & 1.7 & 103 & 29.4 & 216 & 61.7 \\
\hline D6 & 10 & 2.9 & 10 & 2.9 & 11 & 3.1 & 94 & 26.9 & 225 & 64.3 \\
\hline D7 & 9 & 2.6 & 14 & 4.0 & 8 & 2.3 & 107 & 30.6 & 212 & 60.6 \\
\hline $\mathrm{C} 8$ & 13 & 3.7 & 12 & 3.4 & 6 & 1.7 & 96 & 27.4 & 223 & 63.7 \\
\hline D9 & 6 & 1.7 & 15 & 4.3 & 10 & 2.9 & 85 & 24.3 & 234 & 66.9 \\
\hline D10 & 13 & 3.7 & 11 & 3.1 & 10 & 2.9 & 107 & 30.6 & 209 & 59.7 \\
\hline Skor Min & 4.44 & & & & & & & & & \\
\hline Sisishan & & & & & & & & & & \\
\hline Piawai & 0.81 & & & & & & & & & \\
\hline Tahap & Tingg & & & & & & & & & \\
\hline
\end{tabular}

\section{Hubungan antara budaya keusahawanan dan kepimpinan keusahawanan terhadap minda keusahawanan}

Jadual 5 menunjukkan hasil analisis korelasi Pearson bagi menentukan hubungan budaya keusahawanan dan kepimpinan keusahawanan terhadap minda keusahawanan anak-anak golongan Asnaf. Dapatan analisis menunjukkan bahawa terdapat hubungan positif yang signifikan antara budaya keusahawanan terhadap minda keusahawanan iaitu $(\mathrm{r}=0.972, \mathrm{p}<0.001)$. Manakala, dapatan analisis bagi kepimpinan keusahawanan terhadap minda keusahawanan juga menunjukkan hubungan positif iaitu ( $\mathrm{r}=0.890, \mathrm{p}<0.001)$. Menurut Cohen (1988), hubungan kekuatan bagi budaya keusahawanan terhadap minda keusahawanan anak-anak golongan Asnaf adalah sangat kuat. Manakala, hubungan kekuatan bagi kepimpinan keusahawanan terhadap minda keusahawanan anak-anak golongan Asnaf adalah sangat kuat juga.

Jadual 5: Ujian Korelasi Pearson Minda Keusahawanan

\begin{tabular}{llll}
\hline Pemboleh ubah & $\mathbf{r}$ & Sig. & Hubungan \\
\hline Budaya Keusahawanan & 0.965 & $0.000^{*}$ & Sangat Kuat \\
$\begin{array}{l}\text { Kepimpinan } \\
\text { Keusahawanan }\end{array}$ & 0.955 & $0.000 *$ & Sangat Kuat \\
\hline $\begin{array}{l}* \text { Signifikan pada nilai } \mathrm{p}>.001 \\
\text { S }\end{array}$ & &
\end{tabular}

\section{Perbincangan Kajian}

Jelaslah bahawa anak-anak golongan Asnaf perlu mempunyai tahap budaya keusahawanan yang tinggi sebelum menyertai Program Keusahawanan Asnaf supaya program tersebut tidak menemui kegagalan dan menjadi pembaziran kepada dana zakat. Tahap budaya keusahawanan yang tinggi dapat membantu diri usahawan dalam menguruskan perniagaan serta organisasi. Dapatan ini telah mengembangkan kajian oleh Balwi (2008) yang menyatakan bahawa tahap budaya keusahawanan dalam kalangan Asnaf adalah tinggi.

Manakala, tahap kepimpinan keusahawanan anak-anak golongan Asnaf juga berada pada tahap tinggi. Dapatan kajian ini telah mengembangkan kajian oleh Radzi dan Ahmad (2017) yang menyatakan 
bahawa golongan Asnaf perlu mempunyai tahap kepimpinan keusahawanan yang tinggi supaya dapat menguruskan organisasi dengan lebih baik.

Seterusnya, jelaslah juga bahawa anak-anak golongan Asnaf perlu mempunyai tahap minda keusahawanan yang tinggi sebelum menyertai Program Keusahawanan Asnaf. Mempunyai minda keusahawanan merupakan ciri yang penting kerana usahawan perlu mempunyai satu set pemikiran keusahawanan demi meneroka, menilai dan memanfaatkan peluang keusahawanan yang diinginkan. Tahap minda keusahawanan yang tinggi dapat membantu usahawan dalam mencetuskan inovasi serta menyelesaikan masalah-masalah yang dihadapi pengguna. Dapatan ini telah mengembangkan kajian oleh Din et al. (2019) terhadap golongan Asnaf supaya mempersiapkan diri dengan tahap minda keusahawanan yang tinggi sebelum menyertai Program Keusahawanan Asnaf anjuran Lembaga Zakat. Kajian tersebut adalah menyoroti kajian sebelumnya oleh Shiyuti dan Al-Habshi (2018) yang menyatakan bahawa tahap minda keusahawanan yang tinggi adalah diperlukan dan menjadi faktor asas bagi seseorang dalam menceburi bidang keusahawanan.

Hubungan bagi budaya keusahawanan dan kepimpinan keusahawanan terhadap minda keusahawanan adalah sangat kuat. Dapatan ini adalah selari dengan dapatan oleh Hayat et al., (2019) yang menegaskan bahawa budaya keusahawanan dan kepimpinan keusahawanan merupakan faktor yang mempunyai pengaruh yang kuat terhadap minda keusahawanan.

\section{Kesimpulan}

Didapati bahawa tahap budaya keusahawanan, tahap kepimpinan keusahawanan dan tahap minda keusahawanan adalah pada tahap tinggi. Manakala, faktor budaya keusahawanan dan kepimpinan keusahawanan mempunyai hubungan positif yang sangat kuat dengan minda keusahawanan bagi anakanak golongan Asnaf di Selangor. Kajian mendapati bahawa anak-anak golongan Asnaf mempunyai keyakinan yang tinggi untuk menjadi pemimpin keusahawanan dengan berlandaskan budaya-budaya keusahawanan. Anak-anak golongan Asnaf juga mempunyai pemikiran sebagai seorang usahawan yang cukup baik. Justeru, jelaslah bahawa budaya keusahawanan dan kepimpinan keusahawanan mempunyai hubungan positif yang sangat kuat terhadap minda keusahawanan.

Implikasi daripada kajian ini dapat membantu Lembaga Zakat Negeri yang mengagihkan bantuan modal zakat bagi aktiviti keusahawanan untuk memilih anak-anak golongan Asnaf yang mempunyai budaya keusahawanan, kepimpinan keusahawanan serta minda keusahawanan yang tinggi dalam memulakan perniagaan supaya bantuan modal tidak mengalir kepada individu yang tidak mempunyai ciri-ciri keusahawanan yang diperlukan.

Menjawab kepada isu atau permasalahan kajian bahawa Program Keusahawanan Asnaf yang menemui beberapa kegagalan daripada beberapa individu yang menyertai adalah disebabkan tahap budaya keusahawanan, tahap kepimpinan keusahawanan dan tahap minda keusahawanan yang berada pada tahap yang rendah. Justeru, cadangan kajian lanjutan boleh mengkaji lagi beberapa faktor yang difikirkan mempunyai hubungan terhadap minda keusahawanan. Kajian yang lebih lanjut dapat membantu Lembaga Zakat dalam memilih peserta yang berkualiti bagi menyertai Program Keusahawanan Asnaf pada masa akan datang.

\section{Rujukan}

Abai, D. S. A., Awang, M. D., Yusoff, A. N. M., Majid, A. A., \& Hamli, H. (2020). Bentuk Bantuan Modal Agihan Zakat Asnaf dan Pencapaian Usahawan Asnaf di Malaysia: Kajian Empirikal. Malaysian Journal of Social Sciences and Humanities (MJSSH), 5(1), 93-99.

Adnan, N. I. M., \& Roselam, M. A. B. C. (2019). Pengagihan Dana Zakat Dalam Bentuk Pembiayaan Mikro Untuk Usahawan Miskin Di Malaysia: The Distribution of Zakat Fund to the 
underprivileged Enterpreneurs Using Micro Finance in Malaysia. Journal of Fatwa Management and Research, 3(1), 90-104.

Ajzen, I. (1991). The theory of planned behavior. Organizational behavior and human decision processes, 50(2), 179-211.

Ananda, A. F., \& Mukhadis, A. (2016, October). Production unit as edupreneurship, cooperation business and industrial world with the school for the development of vocational student entrepreneurship mindset. In AIP Conference Proceedings (Vol. 1778, No. 1, p. 030048). AIP Publishing LLC.

Balwi, M. A. W. F. M. 2008. Mobilisasi zakat dalam pewujudan usahawan asnaf: satu tinjauan. Jurnal Syariah, 16(3), 567-584.

Bass, B. M., and B. J. Avolio (1995). Multifactor Leadership Questionnaire. Redwood City, CA: Mind Garden.

Bosman, L., \& Fernhaber, S. (2018). Defining the Entrepreneurial Mindset. In Teaching the Entrepreneurial Mindset to Engineers (pp. 7-14). Springer, Cham.

Cameron, K. S., \& Quinn, R. E. (2019). The competing values culture assessment. 1-14.

Capelleras, J. L., Contin-Pilart, I., Larraza-Kintana, M., \& Martin-Sanchez, V. (2019). Entrepreneurs' human capital and growth aspirations: The moderating role of regional entrepreneurial culture. Small Business Economics, 52(1), 3-25.

Cohen, J. (1988). Differences between correlation coefficients. Statistical power analysis for the behavioral sciences, 109-143.

Dabla-Norris, M. E., Kochhar, M. K., Suphaphiphat, M. N., Ricka, M. F., \& Tsounta, E. (2015). Causes and consequences of income inequality: A global perspective. International monetary fund.

De Mooij, M. (2015). Cross-cultural research in international marketing: clearing up some of the confusion. International Marketing Review, 32(6), 646-662.

Din, N. M., Ismail, M., \& Rosli, M. M.(2019). Factors influencing Asnaf Entrepreneur's intention under Asnaf Entrepreneurial Program (AEP) towards zakat on business. Journal of Islamic, 4(22), 11-24.

Duening, T. N., \& Metzger, M. L. (Eds.). (2017). Entrepreneurial identity: The process of becoming an entrepreneur. Edward Elgar Publishing.

Dweck, C. (2017). Mindset: Changing the way you think to fulfil your potential.London, UK: Hachette.

Engelen, A., Gupta, V., Strenger, L., \& Brettel, M. (2015). Entrepreneurial orientation, firm performance, and the moderating role of transformational leadership behaviors. Journal of management, 41(4), 1069-1097.

Fishbein, M., \& Ajzen, I. (1975). Belief, attitude, intention, and behavior: An introduction to theory and research. Reading, Mass: Addison-Wesley.

Fosu, A. K. (2017). Growth, inequality, and poverty reduction in developing countries: Recent global evidence. Research in Economics, 71(2), 306-336.

Fukuyama, F. (2017). The great disruption. Profile Books.

Gabrielsson, M., Gabrielsson, P. \& Dimitratos, P. 2014. International Entrepreneurial Culture and Growth of International New Ventures. Manag Int Rev 54, 445-471.

Galloway, L., Kapasi, I., \& Sang, K. (2015). Entrepreneurship, leadership, and the value of feminist approaches to understanding them. Journal of Small Business Management, 53(3), 683-692.

Halim, H. A., Ahmad, N. H., Ramayah, T., Hanifah, H., Taghizadeh, S. K., \& Mohamad, M. N. (2015). Towards an innovation culture: Enhancing innovative performance of Malaysian SMEs. Academic Journal of Interdisciplinary Studies, 4(2), 85.

Halim, N. H., \& Sahid, S. (2020). Kemahiran Kesediaan Kerja, Efikasi Kendiri, Tingkah Laku Keusahawanan dan Eksplorasi Kerjaya dalam kalangan Graduan (Work Readiness Skills, SelfEfficacy, Entrepreneurial Behavior and Career Exploration among Graduates). Akademika, 90(3), 155-165.

Harrison, C., Paul, S., \& Burnard, K. (2016). Entrepreneurial Leadership: A Systematic Literature Review. International Review of Entrepreneurship, 14(2), 255-264.

Harrison, C., Burnard, K. \& Paul, S. (2018). Entrepreneurial leadership in a developing economy: a skill-based analysis. Journal of Small Business and Enterprise Development, 25(3), 521 -548. 
Hasrul, H. (2016). Pengaruh gaya kepimpinan ke atas orientasi keusahawanan dengan prestasi perniagaan usahawan mikro bumiputera di Kedah [Doctoral dissertation, Universiti Utara Malaysia].

Hassanain, K. M. (2015). Integrating Zakah, Awqaf and IMF for Poverty Alleviation: Three Models of Islamic Micro Finance. Journal of Economic and Social Thought, 2(3), 193-211.

Hayat, A., Latif, A., Humayon, A. A., Ahmed, M., \& Azeem, M. (2019). The mediating role of entrepreneurial leadership in the relationship between entrepreneurial orientation and firm performance of ICTs SMEs. Journal of Multidisciplinary Approaches in Science, 5(1), 16-23.

Haynes, K. T., Hitt, M. A., \& Campbell, J. T. (2015). The dark side of leadership: Towards a midrange theory of hubris and greed in entrepreneurial contexts. Journal of management studies, 52(4), 479-505.

Hoch, J. E., Bommer, W. H., Dulebohn, J. H., \& Wu, D. (2018). Do ethical, authentic, and servant leadership explain variance above and beyond transformational leadership? A metaanalysis. Journal of Management, 44(2), 501-529.

Houghton J. D., \& Neck, C. P. (2002). The Revised Self-Leadership Questionnaire: Testing a Hierarchical Factor Structure For Self-Leadership. Journal of Managerial Psychology, 17, 672690.

Hu, R., Wang, L., Zhang, W., \& Bin, P. (2018). Creativity, proactive personality, and entrepreneurial intention: the role of entrepreneurial alertness. Frontiers in psychology, 9, 951.

Hussiin, H. (2018). Integrasi Kaum Dalam Rancangan Pembangunan Negara: Tumpuan Selepas Dasar Ekonomi Baru. International Journal of Humanities Technology and Civilization, 1, 58-73.

Ireland, R. D., Hitt, M. A., \& Sirmon, D. G. (2003). A model of strategic entrepreneurship: The construct and its dimensions. Journal of management, 29(6), 963-989.

Ishak, Z., Buang, N. A., \& Halim, L. (2017). Ciri-ciri dan Tahap Pemikiran Sains Keusahawanan: Kesediaan Integrasi Pemikiran Keusahawanan Dalam Proses Pengajaran Guru-guru Sains di MRSM. JuPiDi: Jurnal Kepimpinan Pendidikan, 1(1), 53-64.

Islam, R., Ghani, A. B. A., Abidin, I. Z., \& Rayaiappan, J. M. (2017). Impact on poverty and income inequality in Malaysia's economic growth. Problems and perspectives in management, 15(1), 5562.

Jabeen, F., Faisal, M. N., \& Katsioloudes, M. I. (2017). Entrepreneurial mindset and the role of universities as strategic drivers of entrepreneurship. Journal of Small Business and Enterprise Development, 24(1), 136-157.

Jaiswal, N. K., \& Dhar, R. L. (2015). Transformational leadership, innovation climate, creative selfefficacy and employee creativity: A multilevel study. International Journal of Hospitality Management, 51, 30-41.

Jyoti, J., \& Bhau, S. (2015). Impact of transformational leadership on job performance: Mediating role of leader-member exchange and relational identification. Sage Journals, 5(4), 215-230.

Kassim N. A., \& Buyong, S. Z. \& Kasmarini B. (2014). Information needs of people with entrepreneurial intentions. International Journal of Academic Research, 6, 35-39.

Klein, G. A. (2017). Sources of power: How people make decisions. Boston, MA: MIT Press.

Krejcie, R. V., \& Morgan, D. W. (1970). Determining sample size for research activities. Educational and psychological measurement, 30(3), 607-610.

Kirkley, W. W. (2016). Entrepreneurial behaviour: the role of values. International Journal of Entrepreneurial Behavior \& Research, 22(3), 290-328.

Krueger, N. F. (2017). Entrepreneurial intentions are dead: Long live entrepreneurial intentions. In Revisiting the entrepreneurial mind (pp. 13-34). Springer, Cham.

Leitch, C. M., \& Volery, T. (2017). Entrepreneurial leadership: Insights and directions. International Small Business Journal, 35(2), 147-156.

Lumpkin, G. T., \& Dess, G. G. (1996). Clarifying the entrepreneurial orient ation construct and linking it to performance. Academy of Management Review, 21: 135-172.

Makri, M., and T. A. Scandura (2010). "Exploring the Effects of Creative CEO Leadership on Innovation in High-Technology Firms," The Leadership Quarterly 21(1), 75-88.

Manurung, S. (2015). The Influence of Entrepreneurial Mindset Towards Product Innovation:(Case Study on Mom's Bakery in Bandung). 2nd International Conference for Emerging Markets. http://dx.doi.org/10.2139/ssrn.2877505 
Marzuki, N., Zulkifli, S., \& Wahid, H. (2019). Pengukuran kejayaan bantuan modal perniagaan usahawan asnaf dalam konteks pencapaian maqasid al-shariah. Kajian di daerah Kuala Terengganu dan Kuala Nerus, Terengganu. Jurnal Syariah, 27(2).

McGrath, R.G. and I. MacMillan. (2000). The Entrepreneurial Mindset. Harvard Business School Press

Mehtap, S., Pellegrini, M. M., Caputo, A., \& Welsh, D. H. (2017). Entrepreneurial intentions of young women in the Arab world. International Journal of Entrepreneurial Behavior \& Research, 23(6), 880-902.

Mittal, S., \& Dhar, R. L. (2015). Transformational leadership and employee creativity. Management Decision, 53(5), 894-910.

Mokhber, M., Tan, G. G., Vakilbashi, A., Zamil, N. A. M., \& Basiruddin, R. (2016). Impact of Entrepreneurial Leadership on Organization Demand for Innovation: Moderating Role of Employees' Innovative Self-Efficacy. International Review of Management and Marketing, 6(3), 301-316.

Najwa, M. (2017). Ekonomi Politik Institusi Zakat: Satu Penelitian Terhadap Institusi Zakat di Pulau Pinang. Jurnal Syarikah: Jurnal Ekonomi Islam,3(1), 330-342.

Nambisan, S., Siegel, D., \& Kenney, M. (2018). On open innovation, platforms, and entrepreneurship. Strategic Entrepreneurship Journal, 12(3), 354-368.

Nieto, M., \& González-Álvarez, N. (2016). Social capital effects on the discovery and exploitation of entrepreneurial opportunities. International Entrepreneurship and Management Journal, 12(2), 507-530.

Obschonka, M., \& Stuetzer, M. (2017). Integrating psychological approaches to entrepreneurship: the Entrepreneurial Personality System (EPS). Small Business Economics, 49(1), 203-231.

Oviatt, B. M., \& McDougall-Covin, P. (2015). International entrepreneurship. Wiley Encyclopedia of Management.

Radzi, N. M., \& Ahmad, N. A. (2017). Peranan zakat dalam meningkatkan ekuiti dalam pendidikan anak-anak miskin bandar di Malaysia. JuPiDi: Jurnal Kepimpinan Pendidikan, 4(3), 1-13.

Ravallion, M. (2019). Ethnic Inequality and Poverty in Malaysia Since 1969. National Bureau of Economic Research, 2(3), 320-335.

Renko, M., El Tarabishy, A., Carsrud, A. L., \& Brännback, M. (2015). Understanding and measuring entrepreneurial leadership style. Journal of small business Management, 53(1), 54-74.

Ruben, B. D., \& Gigliotti, R. A. (2016). Leadership as social influence: An expanded view of leadership communication theory and practice. Journal of Leadership \& Organizational Studies, 23(4), 467-479.

Shafique, I., \& Kalyar, M. N. (2018). Linking transformational leadership, absorptive capacity, and corporate entrepreneurship. Administrative Sciences, 8(2), 9.

Shepherd, D. A., Williams, T. A., \& Patzelt, H. (2015). Thinking about entrepreneurial decision making: Review and research agenda. Journal of management, 41(1), 11-46.

Shiyuti, H. A., \& Al-Habshi, S. M. (2018). An Overview of Asnaf Entrepreneurship Program by Lembaga Zakat Selangor, Malaysia. In 6th ASEAN Universities International Conference on Islamic Finance (AICIF), Manila, Philippines 14th \& 15th November.

Short Jr, J. F. (2018). Poverty, ethnicity, and violent crime. Routledge.

Silva, A. (2014). What do we really know about leadership?. Journal of Business Studies Quarterly, 5(4), 275-290.

Sirkin, R. M. (2005). Statistics for the social sciences. Sage Publications.

Sklaveniti, C. (2017). Processes of entrepreneurial leadership: Co-acting creativity and direction in the emergence of new SME ventures. International Small Business Journal, 35(2), 197-213.

Subramaniam, R., \& Shankar, R. K. (2020). Three Mindsets of Entrepreneurial Leaders. The Journal of Entrepreneurship, 29(1), 7-37.

Taber, K. S. (2018). The use of Cronbach's alpha when developing and reporting research instruments in science education. Research in Science Education, 48(6), 1273-1296.

Volery, T., Mueller, S., \& von Siemens, B. (2015). Entrepreneur ambidexterity: A study of entrepreneur behaviours and competencies in growth-oriented small and medium-sized enterprises. International Small Business Journal, 33(2), 109-129. 
Wales, W., Gupta, V. K., Marino, L., \& Shirokova, G. (2019). Entrepreneurial orientation: International, global and cross-cultural research. International Small Business Journal, 37(2), 95104.

Yun, J. J., Zhao, X., Jung, K., \& Yigitcanlar, T. (2020). The culture for open innovation dynamics.

Yunus, H. M., \& Ahmad, A. R. (2016). Kemahiran Insaniah Ke Arah Pembentukan Potensi Pelajar. In Proceeding 7th International Seminar on Regional Education: Vol 1, 198-215.

Zainal, H., Basarud-din, S. K., Yusuf, R. M., \& Omar, S. N. Z (2016). Managing zakat fund in malaysia. Journal of Global Business and Social Entrepreneurship, 1(2), 46-53.

Zainol, F. A., Daud, W. N. W., Shamsu, L., Abubakar, H. S., \& Halim, H. A. (2018). A linkage between entrepreneurial leadership and SMEs performance: An integrated review. International Journal of Academic Research in Business and Social Sciences, 8(4), 104-118. 